\title{
Analysis on Injury Characteristics of Child Passenger in China's Traffic Accidents
}

\author{
Kai Liu, ${ }^{1,2, a}$, Yubin Qian", Lingyun Xiao ${ }^{2, b, *}$, Honglei Dong ${ }^{2}$, Wenhao $\mathrm{Hu}^{2}$, Xianguo $\mathrm{Qu}^{2}$ \\ ${ }^{1}$ School of Automotive Engineering, Shanghai University of Engineering Science, Shanghai 201620, China; \\ ${ }^{2}$ AQSIQ Defective Product Administrative Center(DPAC), Beijing 100101, China. \\ a1065790643@qq.com, bxiaoly@dpac.gov.cn
}

Keywords: NAIS; traffic accidents; child passengers; injury characteristics

\begin{abstract}
Injury characteristics of child passengers in accidents are summarized in this paper. Based on the accident data about child passengers from 2011 to 2017 collected in the National Automobile Accident In-Depth Investigation System (NAIS), the analysis of the patterns of the traffic accident where child passengers are involved and injury characteristics of child passengers in the aspects of crash overlapping rate, crash speed and location of child passenger in the vehicle is conducted. The results show that: among the 62 accident cases where child passengers are involved, the accident with $25 \%-50 \%$ overlapping rate has the highest accident rate and the highest child injury rate; the number of the accidents at crash speed below $80 \mathrm{~km} / \mathrm{h}$ accounts for $80.6 \%$; the casualty rate of the child passenger in the rear row seat is lower than that of the child in front row seat. Based on the above analysis, this study can provide data support for the establishment of child safety legislation and the improvement of crash test standard of child restraint system.
\end{abstract}

\section{Introduction}

Child-involved traffic accident refers to the road traffic accident where the injured is under 14 years old [1]. From 2001 to 2014, the number of death among Chinese children in traffic accidents showed a downward trend, as shown in Fig. 1 [1]. Although the number of children died in traffic accidents is decreasing year by year, the number is still at a high level. Traffic accident is still an important cause resulting in casualties of Chinese children.

The foreign research on the investigation in the child-involved traffic accidents began earlier. The relevant accident statistics show that child who takes the rear seats and uses restraint system can effectively ensure the safety[2] [3] [4] and its safety is far more than that of by only using three-point adult seat belts [5]; the child who only use adult seat belts are more likely to be damaged on the head and neck in traffic accidents [6]; moreover, the severe injury rate of the child passengers using the restraint system can be reduced to $77 \%$ than those who are not protected [7]. A large number of accident data show that the child's head is primarily protected, followed by chest and abdomen [8].

On the other hand, China starts the research on the safety of child passengers in a relatively late of child restraint systems is mainly embodied in the development of new child restraint systems, including integral child seat [9] and embedded child seat [10]. The optimization of child restraint systems is mainly focused on the study about key parameters of child restraint systems by using CAE simulation means, so as to reduce the child damage parameters during the crash process [11] [12]. The study about misuse of the child restraint systems was mainly to research and analyze the misuse situation existing in China [13] [14], find the key model of misuse and propose the corresponding method for evaluating the ease-of-use of child restraint systems [15]. However, there is a relative lack of research on the child casualty statistics, accident patterns, causes and other respects. 


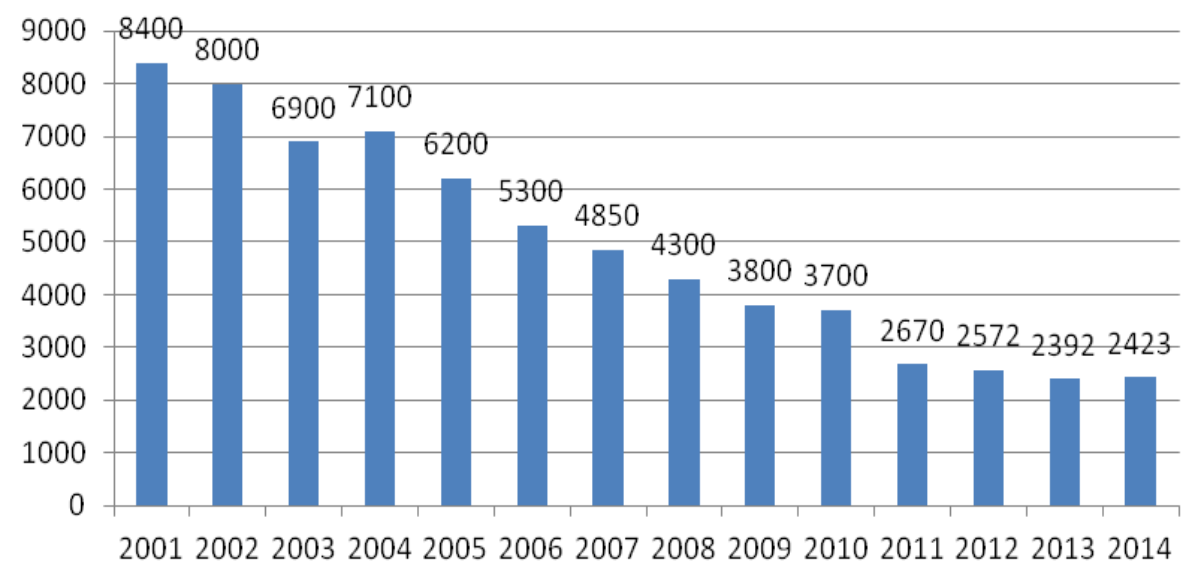

Figure 1 Profile of changes in the number of child deaths in traffic accidents

The analysis of the injury characteristics of child passengers in traffic accidents in China is done from the aspects of crash overlapping rate, crash speed and child location in car by taking examples from the accident cases involving child passengers in the NAIS. The method of in-depth investigation on traffic accidents is adopted to analyze the degree of injury of child passengers in traffic accidents. These real accident data can provide support for the establishment of child safety regulations and improvement of the crash test standard of child restraint systems.

\section{Characteristics of accident data}

The traffic accident data showed in this paper are from the database of the National Accident In-depth Investigation System (NAIS) [16], which was established by the AQSIQ (General Administration of Quality Supervision, Inspection and Quarantine) Defective Product Administrative Center (DPAC) in August 2011. As of June 2017, eight sites have been established in the country, mainly covering North China, East China, southwestern, central and northeastern regions of China. For more details, see Figure 2. The accident sample is representative.

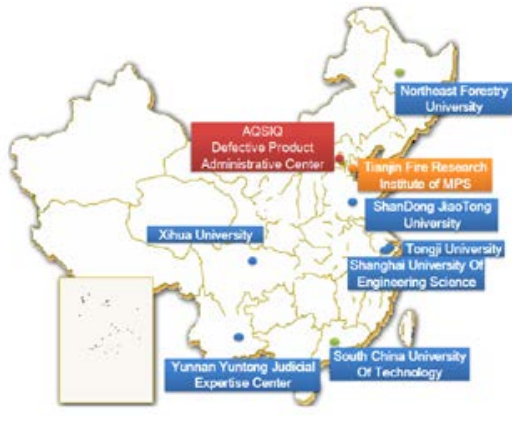

Figure2 NAIS chart

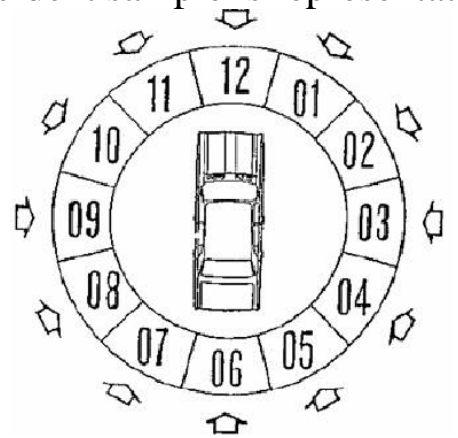

Figure3 Vehicle crash mechanics direction diagram

The accident in-depth investigation process usually refers to the in-depth analysis on the specific causes, road conditions, crash process and consequences of accidents conducted by the university researchers, engineering and technical personnel, medical experts and those experts from traffic management authorities, including crash contact parts, contact range, vehicle crash speed, crash site and passenger's injury etc. Based on this data, we can analyze the degree of passenger injury under different crash conditions. Meanwhile, the typical accident samples are the important basis for accident reconstruction, which can provide reference for the development of crash regulations and improvement in vehicle safety.

This paper analyzes 2,737 accident cases included in the NAIS database from August 2011 to June 2017. These accident cases are screened and selected in accordance with the following requirements:

(1) The type of crash occurred to the vehicle where child passenger seats shall be a front crash;

(2) The crash force shall be between Point 10 and Point 2 as shown in Figure 3; 
(3) In case of occurring crash several times, front crash shall be the most serious crash condition;

(4) Rear-end crash occurs between the passenger cars and the trucks equipped with the rear protective guardrail in accordance with the regulatory requirements.

According to the above requirements, 62 samples are selected, involving 62 passenger cars and 67 child passengers, where 15 child passengers sit in front row sear and 52 child sit in back row seats. There is only one case where child restraint system is used. The total number of casualties is 33, where 16 were slightly injured, 4 were seriously injured and 13 were killed.

\section{Analysis about crash overlapping rate and equivalent barrier speed}

\subsection{Analysis about crash overlapping rate}

At present, the pattern of international front crash test is mainly divided into two systems: the United States' FMVSS and the European Union's ECE. The crash test laws and regulations existing in other countries are developed by referring to these two systems. It mainly includes three test patterns, i.e. 100\% rigid fixed barrier crash test (100\% RB), 40\% offset deformable barrier crash test (40\% ODB) and $30^{\circ}$ angle crash test methods [17]. In order to allow the crash test method to cover as many actual traffic accidents as possible, the US Insurance Institute for Highway Safety (IIHS) promulgated a 25\% small overlapping offset crash test in August 2012 [18]. The comparison about all kinds of crash patterns is shown in Table 1.

\begin{tabular}{cc} 
Table1 & Front crash patterns \\
\hline & $\begin{array}{c}\text { Crash Angle and } \\
\text { Overlapping Rate }\end{array}$ \\
\hline $\begin{array}{c}\text { European Union's } \\
\text { ECE R94/01 }\end{array}$ & $40 \%$ offset \\
United States' & $100 \%$ \\
FMVSS 208 & $30^{\circ}$
\end{tabular}

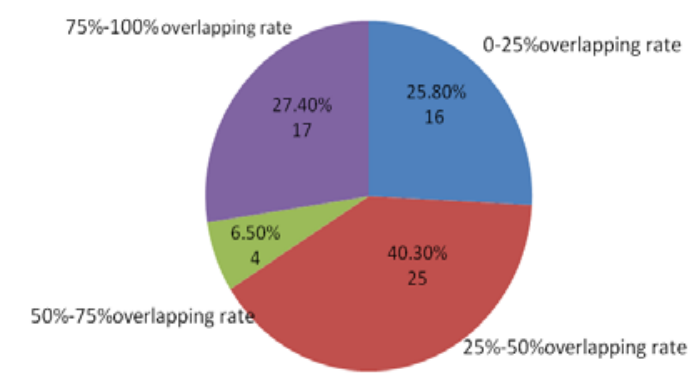

IIHS $\quad 25 \%$ offset

Figure 4 Vehicle crash mechanics direction diagram

This paper divides the crash overlapping rate into four categories with reference to the existing patterns of front crash in the world, i.e. 0-25\% small offset crash, $25 \%-50 \%$ offset crash, $50 \%$ $-75 \%$ offset crash and 75\%-100\% large overlapping crash.

Among the 62 accident vehicles, the number of accident vehicles with four crash overlapping rates respectively reached 16 units, 25 units, 4 units and 17 units. For more details, see Figure 4 . In these patterns, $25 \%-50 \%$ overlapping rate accounts for the highest with the frequency of $40.3 \%$, which shows that offset crash in the actual traffic accidents has a very high proportion; the follow is $75 \%-100 \%$ overlapping rate with the frequency of $27.4 \%$; and these two crash patterns are subject to higher frequency.

According to the studies, in case of involving in 40\% ODB crash, in addition to causing a greater challenge against body structure, there are also requirements on vehicle constraint systems [19]. In 100\% RB crash, because the front part of the body is fully involved in the crash and the body is crashed at the peak acceleration, the protection performance of vehicle restraint system can be investigated to the greatest extent.

\subsection{Analysis about equivalent barrier speed in crash}

According to the China's national standards related to front crash, crash speed refers to the crash speed of the vehicle relative to wall barrier in the laboratory. This speed value is equivalent to the equivalent barrier speed calculated based on vehicle deformation in the traffic accident [20]. It is required to measure the specific deformation of vehicle's front part, as shown in Figure 5. In the NHTSA Database, enter the specific vehicle model and input specific vehicle deformation value (not less than 5 points) in the "Vehicle Crash", so as to get the vehicle's equivalent barrier speed 
(EBS).

Based on the above method, PC-Crash software is used to analyze and access to the vehicle's equivalent barrier speed. The concrete distribution is shown in Figure 6. It can be seen from the figure that the largest number of accidents occurred at the speed in the range of $50 \sim 60 \mathrm{~km} / \mathrm{h}$, totaling 12 cases; the accidents occurred at the speed bellow $60 \mathrm{~km} / \mathrm{h}$ accounted for $54.8 \%$; and the accidents occurred at the speed below $80 \mathrm{~km} / \mathrm{h}$ accounted for $80.6 \%$. This shows that the traffic accidents occurred at the speed of $60-80 \mathrm{~km} / \mathrm{h}$ also has a certain proportion in China's actual traffic accidents. In 2012, China's C-NCAP increased the speed of $56 \mathrm{~km} / \mathrm{h}$ to $64 \mathrm{~km} / \mathrm{h}$ used in $40 \%$ ODB crash test [21]. The improvement is consistent with the characteristics of speed in China's actual traffic accidents.

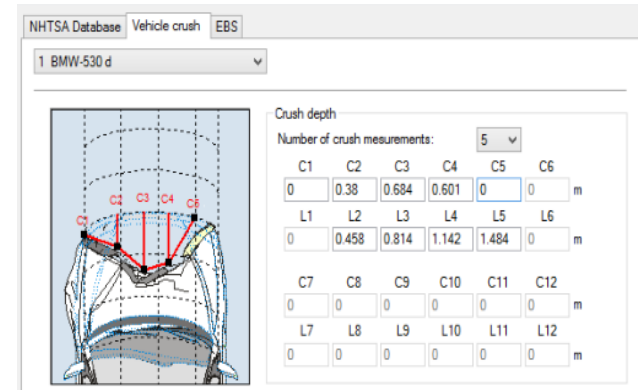

Figure 5 Deformation of vehicle's front part

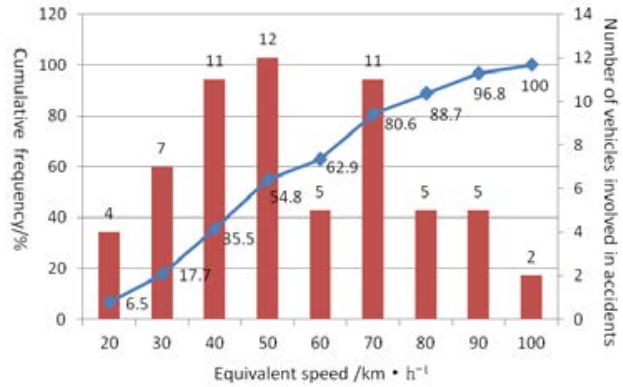

Figure 6Equivalent barrier speed distribution in vehicle crash

\section{Analysis about characteristics of injuries to child passengers}

The casualty information mainly includes the injured parts (head, neck, chest, abdomen and lower limbs), degree of injury (according to the Abbreviated Injury Scale, AIS) based on human anatomy Grade, there are six levels: AIS 1 AIS 6) and cause of death (craniocerebral injury, respiratory system failure, traumatic hemorrhagic shock and combined injury caused in traffic accident) of child passengers. The basis for injury classification is showed in Table 2.

Table 2 Basis for injury classification

\begin{tabular}{cc} 
AIS Level & Degree of Injury \\
\hline 0 & No injury \\
1 & Minor injury \\
2 & Slight injury \\
3 & Heavy injury \\
4 & Major injury \\
5 & Fatal injury \\
& \\
6 & Incurable
\end{tabular}

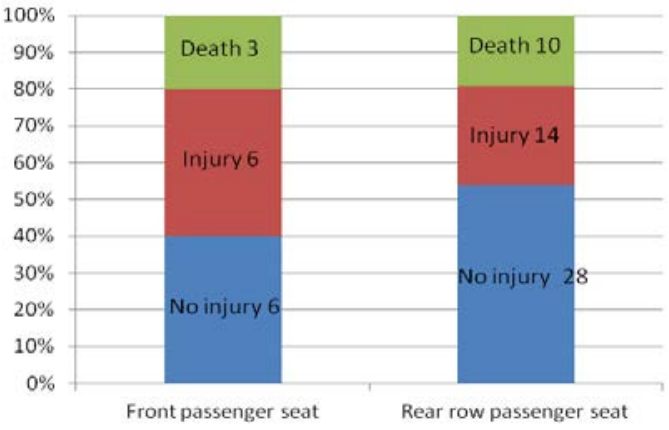

Figure 7 Distribution of injuries to child passengers sit in front and rear row seats

According to the above-mentioned basis for injury classification, it specifies that child passenger is not injured for AIS0, slightly injured for AIS1 2, seriously injured for AIS3 4; and for AIS5 6, the state of injury to child passenger shall be determined in the specific circumstances: if child passengers died on the scene or after seven days since being treated in hospital, it shall be determined as the injury to death; otherwise, it shall be determined as seriously injured.

67 child passengers are classified by seat location. 15 children sit in the front passenger seat and another 52 children sit in rear row seat. The specific injuries to child passengers are showed in Figure 7.As shown above, the casualty rate of the child passengers sitting in front row seat was $60 \%$, while the casualty rate of the child passengers sitting in rear row seat was $46.2 \%$. It can be seen that the probability of injury of the child passengers sitting in front row seat is greater than that of in rear row seat. However, the casualty rate of child passenger independently sitting in rear row seat is also higher because the child restraint systems are less used. Therefore, correct use of child restraint systems in rear row seat can effectively protect child's safety during driving. 


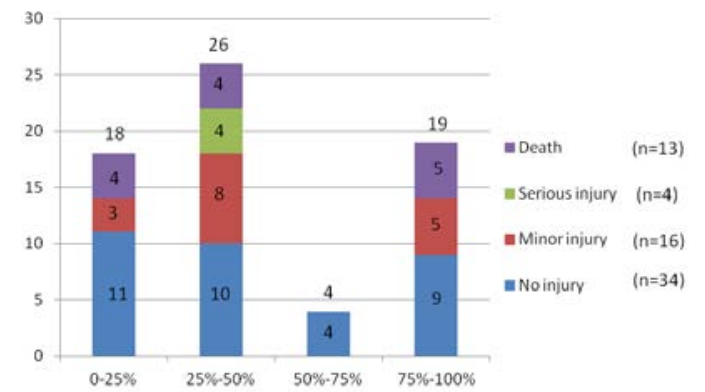

Figure 8 Relationship between injury characteristics of child passengers and crash type

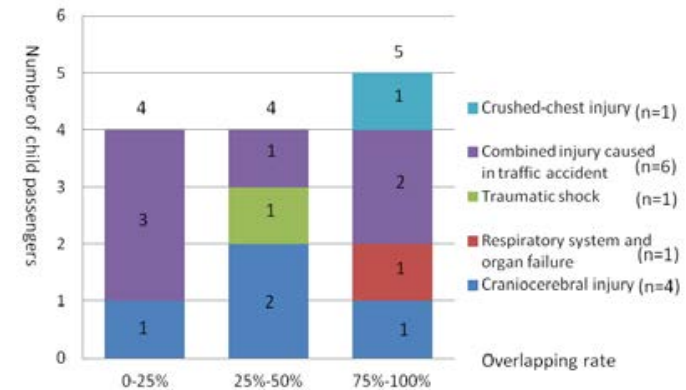

Figure 9 Relationship between cause of death and crash type

The injury characteristics of child passengers and death causes are statistically analyzed by types of crash. For more details, see Figure 8 and Figure 9. The figures show that when the crash overlapping rate is $25 \% \sim 50 \%$, the proportion of casualties of child passengers was the highest, reaching $61.5 \%$; followed by $75 \% \sim 100 \%$ large overlap crash, the proportion of casualties of child passengers reached $52.6 \%$. In addition, $47 \%$ serious injury and death cases occurred in the overlapping rate of $25 \% \sim 50 \%$. It can be seen that the casualties of child passengers are more seriously injured in the case of offset crashes.

When the vehicle 25\% 50\% offset crash occurs, as only a side of body is involved in the crash, the vehicle may has angular deflection in the process of vehicle crash, resulting in the secondary crash between child passengers and the vehicle's interior parts and leading to casualties; when the vehicle occurs $75 \% \sim 100 \%$ overlapping rate crash, because the energy absorption structure in front of the vehicle is almost involved in the crash, resulting in a larger vehicle acceleration peak, which may cause fatal injuries on child's head and chest at high speed. It can be seen from Figure 9, more child passengers died due to combined injury in the case of $25 \%$ 50\% offset crash, while more child passengers were suffered from fetal injury on head or chest in the case of $75 \% \sim 100 \%$ offset crash.

\section{Analysis about typical cases}

At 20:10 pm, Car A drove from west to east and Car B drove from east to west. Because the driver in Car A was driving and driving in the wrong direction, resulting in crash between the left front of Car A and the left front of Car B in normal driving. In this accident, the left front of Car A was generally damaged and rotated about $40^{\circ}$ in counterclockwise, while the left front of Car B was generally damaged and Car B moved back about 3.5m with slight rotation in counterclockwise. The specific accident process is as shown in Figure 10. When the accident occurred, the front airbags in two cars were triggered; the driver in Car A did not use seat belt and died on the spot; and the driver in Car B was slightly injured due to use of seat belt, the passenger in the rear right seat did not use seat belt and was generally injured, the child passenger sitting in the rear middle seat did not use seat belts and was seriously injured.

The exterior damage on Car B shows that Car B damage width is about $58 \mathrm{~cm}$, as shown in Figure 11, and the damage width accounted for 33\% of the vehicle width.Based on PC-Crash simulation analysis, before the crash, Car A was driving at the speed of $68 \mathrm{~km} / \mathrm{h}$ and EBS was $33 \mathrm{~km} / \mathrm{h}$; Car B was driving at the speed of $20 \mathrm{~km} / \mathrm{h}$ and EBS was $31 \mathrm{~km} / \mathrm{h}$. Both cars met the conditions of triggering airbag burst. During the accident, the child passenger in the rear middle seat collided with the central armrest in the front row because of no protective measures, resulting in abdominal and facial abrasions, right femur fracture and chest contusion. The damage of the central armrest in the front row is as shown in Figure 12. 


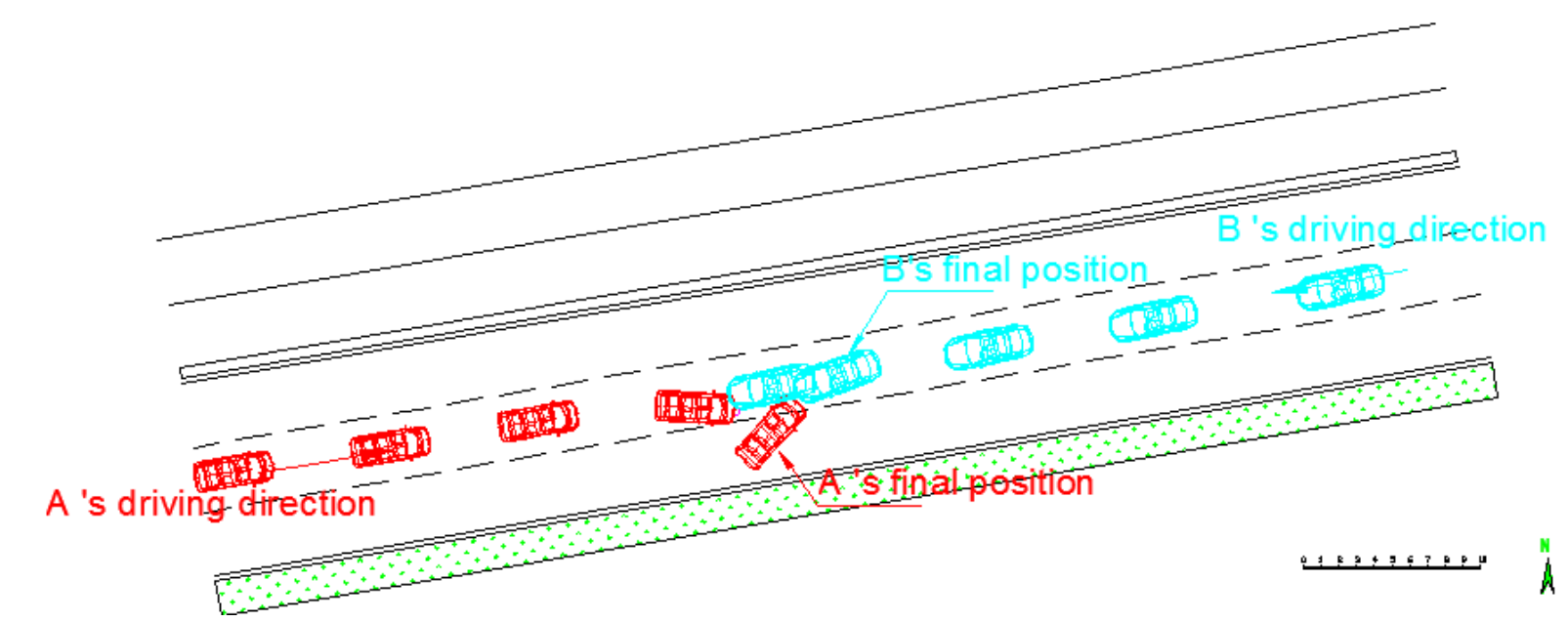

Figure10 Accident process diagram

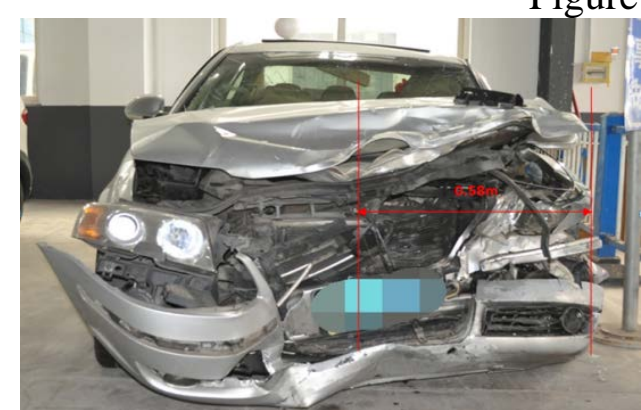

Figure11 Car B damage width diagram

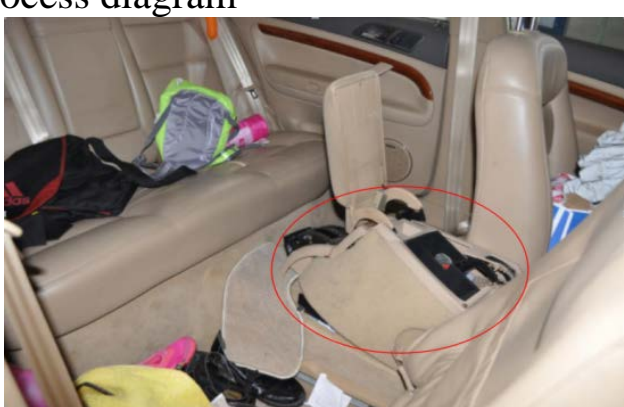

Figure12 Damage of central armrest in the front row

In the above traffic accident, when the car occurred offset crash, because the child passenger in the rear middle seat did not take any protective measures, the child passenger collided with the central armrest in the front row under the action of inertial force forward movement, leading to many injuries to the body. In order to further explore the injury characteristics of child passengers in traffic accident, this paper explains the actual car crash test under the conditions of different positions where child passenger sits and different protective measure taken, so as to carry on the qualitative analysis about injury to child passenger when the accident happened.

The actual vehicle crash test was carried out under the conditions of $100 \%$ front rigid barrier crash at the speed of $40 \mathrm{~km} / \mathrm{h}$. An adult dummy is placed in the front passenger seat and embraces a P1.5 dummy, Q3 dummy is placed in child safety seat in rear left seat and P6 dummy is placed in rear right seat with safety belt. The details are shown in Figure 13. The state of all dummies after the test is shown in Figure 14.

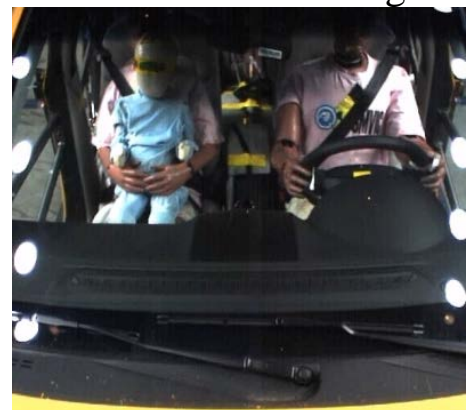

(a) P1.5 dummy in front passenger seat

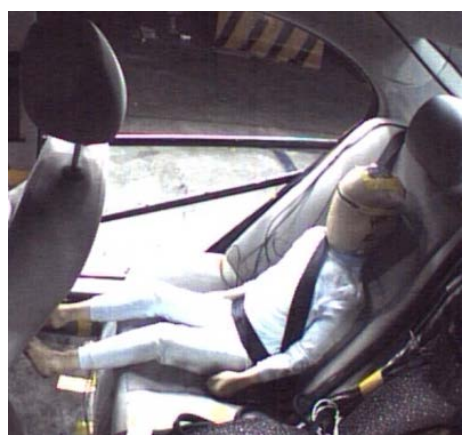

(b) P6 dummy in rear left seat

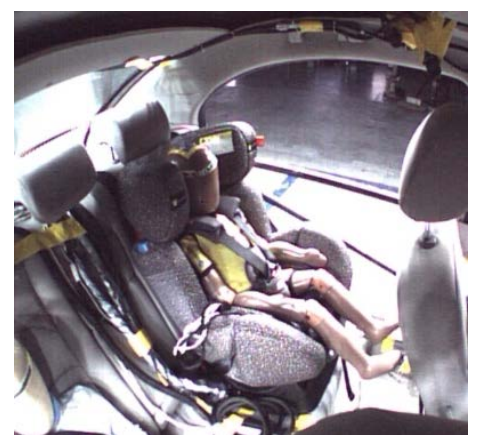

(c) Q3 dummy in rear row seat

Figure13 Restraint on dummy children before crash 


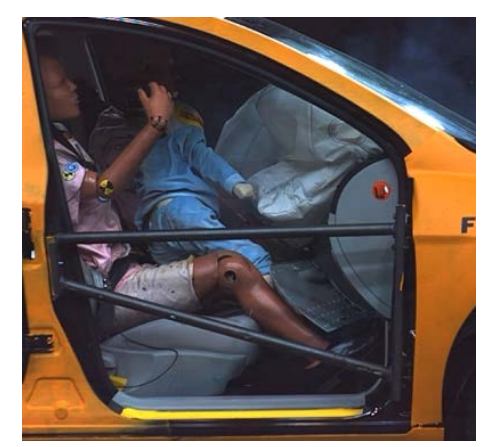

(a) P1.5 dummy in front passenger seat

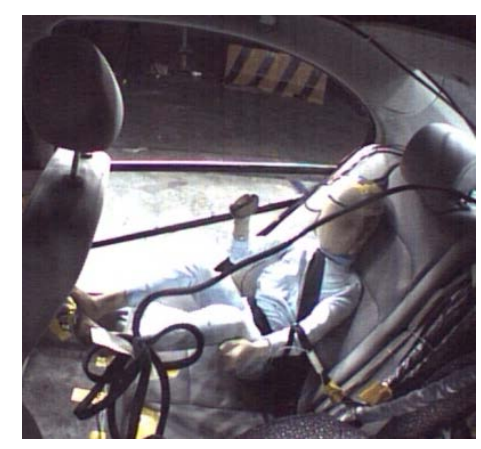

(b) P6 dummy in rear left seat

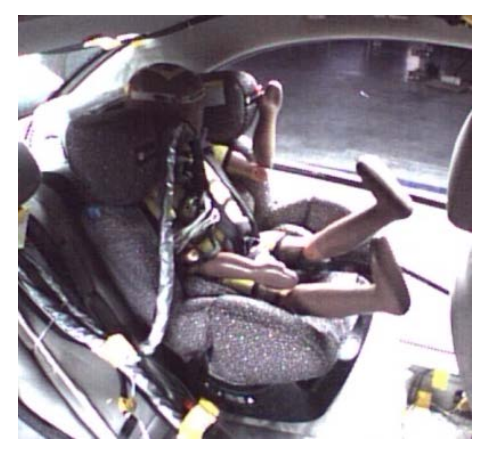

(c) Q3 dummy in rear row seat

Figure14 Restraint on dummy children after crash

As seen from Figure 14 (a), when the adult embraces a child in the front passenger seat, the adult body moves forward and may squeeze the child in the accident process after airbag opens; then, the child may be divorced from the adult's hands, completely unconstrained and collided with interior parts, resulting in secondary damage. As seen from Figure 14 (b), when the child sits in the rear seat with adult seat belt, the child's neck may be curbed by the adult seat belt in the accident process, resulting in crashed-neck injury on the child. As seen from Figure 14 (c), child's safety seat, undoubtedly, has the best protection effect on the child passenger in the above three child restraint systems. When the accident occurs, five-point seat belt well shares the pressure on the child body caused by leaning forward and constraints the child's head displacement in a certain range to avoid the child's key parts to collide with the car interiors, which play a protective effect on the child.

\section{Conclusions}

(1)Two types of crash at the highest frequency are $25 \%$ 50\% overlapping rate and $75 \% \sim 100 \%$ overlapping rate. Under these two types of crash, the proportion of serious injuries and deaths of child passengers is high and the characteristics of casualties are different. It indicates that these two crash patterns can fully cover the front crash patterns existing in real traffic accidents.

(2) The crash accident rate is $54.8 \%$ at the speed below $60 \mathrm{~km} / \mathrm{h}$ and $80.6 \%$ at the speed below $80 \mathrm{~km} / \mathrm{h}$. It indicates that China's actual traffic accident at the speed of $60-80 \mathrm{~km} / \mathrm{h}$ has a certain proportion, which shall be fully considered in the front crash test standards.

(3) During accidents, the casualty rate of child passengers in the front seat is higher than that in rear row seat and the utilization rate of child restraint systems is very low. It indicates that child's safety regulations should take full account of the child position in vehicle and use of child restraint systems.

In summary, most of child passenger injury accident overlapping rates is distributed in the ranges of $25 \% \sim 50 \%$ and $75 \%-100 \%$. Among the current international front crash test methods, $100 \%$ rigid fixed-barrier crash test can effectively replace the traffic accident at $75 \%$ 100\% overlapping rate and $40 \%$ offset deformable barrier crash test can effectively replace the traffic accident at 25\% 50\% overlapping rate. The dynamic performance test method for child restraint system specified in China's current laws and regulations related to child restraint system in vehicles only includes front crash and rear-end crash. In particular, front crash test method cannot fully evaluate the safety performance of child restraint systems by using single crash pattern. Only 40\% offset variability barrier crash test is included in China's current laws and regulations related to dynamic crash test on child restraint systems for the purpose of evaluating the safety performance of child restraint systems in a comprehensive way. With reference to vehicle speed in crash accidents, it is recommended to set the test speed as $64 \mathrm{~km} / \mathrm{h}$ in $40 \%$ offset deformable barrier crash test, so that it can match the patterns of the road traffic accident crash in China. It is also recommended that the child safety regulation shall include the mandatory requirement that the child restraint systems must be mounted in the rear row seat for the child passengers under 14 years old. 


\section{Acknowledgements}

We appreciate National Fund for Fundmental Research (Project ID:282015Y-4005, 282016Y-4500, 282017Y-5303). We also thank all the people who have contributed to this study.

\section{References}

[1] Zhang Jinhuan, Xu Shucai, Yang Xin, et al. Child Occupant Injury and Protection in Motor Vehicle Crashes. Beijing: Tsinghua University Press, 2015

[2] Durbin, D.R., et al., Effects of seating position and appropriate restraint use on the risk of injury to children in motor vehicle crashes. Pediatrics, 2005. 115(3): p. 305-309.

[3] Durbin, D.R., M.R. Elliott, and F.K. Winston, Belt-positioning booster seats and reduction in risk of injury among children in vehicle crashes. JAMA, 2003. 289(21): p. 2835-40.

[4] Elliott, M.R., et al., Effectiveness of child safety seats vs seat belts in reducing risk for death in children in passenger vehicle crashes. Arch Pediatr Adolesc Med, 2006. 160(6): p. 617-21.

[5] Hummel T.H., Langwieder K., Finkbeiner F., et al. Injury risks, misuse rates and the effect of misuse depending on the kind of child restraint system. SAE 973309,1997

[6] Khaewpong N., Nguyen T., Bents F.,et al. Injury severity in restrained children in motor vehicle crashes. SAE 952711,1995

[7] Isaksson-Hellman I., Jakobsson L., Gustavsson C., et al. Trends and effects of child restraint systems based on Volvo's Swedish accident database. SAE 973299, 1997

[8] Jager K., Ratingen M., Lesire P., et al. Assessing New Child Dummies and Criteria for Child Occupant Protection in Frontal Impact. 19th Enhanced Safety of Vehicles Conference. Washington D.C. Paper No. 05-0157, 2005,1-15

[9] LU Jing. A study on optimization matching and design method of integrated child restraint system.[D]. Hunan University.2013

[10] information on http://www.pcauto.com.cn/qcyp/flsq/qcaqyp/0709/543294.html .

[11] ZHU Yun. Analysis on parameter sensitivity of child restraint system based on vehicle frontal crash. [D]. Tongji University.2009

[12] YANG Jikuang, YANG Xingmei, ZHANG Chaochen. Multi-objective Optimization of Child Restraint System for Vehicle Side Impact. [J]. JOURNAL OF MECHANICAL ENGINEERING.2011, Vol. 47 No.12

[13] ZHANG Jinhuan, ZHANG Xiong, XIAO Lingyun, et al. Experimental studies on safety when child restraint system (CRS) misused. J Automotive Safety and Energy, 2014, Vol. 5 No.1

[14] Chen Xiaojun. Cross-sectional Survey on Child Safety Restraint Use and Intervention Study. Shantou University. 2014.

[15] Zhang Xiong. Research on Ease of Use Rating System for Vehicle Child Restraint System[D]. Tsinghua University, 2014.

[16] information on http://www.dpac.gov.cn/NAIS/.

[17] Sun Zhendong, LIU Yuguang,Zhu Xichan. A Study on Some Typical Vehicle Frontal Crash Test Programs[J]. Automotive Engineering.2006, Vol. 28 No.7

[18] Sun Zhendong, Liu Yuguang. A Study on the Injury Characteristics of Rear Seat Occupant in Vehicle Frontal Crash Test[J]. Automotive Engineering.2011, Vol. 33No.8

[19] Insurance Institute for Highway Safety (IIHS). Small overlap crashes [R]. IIHS Status Report, 2012, 47(6). 
[20] Chen Junyi, Wang Hongyan, Pan Ting. On the Types of Vehicle Frontal Crash Test in China Based on Road Traffic Accident Research[J]. Automotive Engineering.2010, Vol. 32No.2

[21] China-New Car Assessment Program[S]. China Automotive Technology \& Research Center. 2012,8:12-45. 